Syracuse University

From the SelectedWorks of Ambika Krishnakumar

2010

Healthy eating and harambee: Curriculum development for a culturally-centered biomedically oriented nutrition education program to reach African American women of childbearing age

Ambika Krishnakumar, Syracuse University

S Kannan

A V Sparks

J D Webster

J Lumeng 


\title{
Healthy Eating and Harambee: Curriculum Development for a Culturally-Centered Bio-Medically Oriented Nutrition Education Program to Reach African American Women of Childbearing Age
}

\author{
Srimathi Kannan · Arlene V. Sparks • \\ J. DeWitt Webster · Ambika Krishnakumar • \\ Julie Lumeng
}

Published online: 5 August 2009

(C) Springer Science+Business Media, LLC 2009

\begin{abstract}
The purpose was to develop, implement and evaluate a peer-led nutrition curriculum Healthy Eating and Harambee that addresses established objectives of maternal and infant health and to shift the stage for African American women of childbearing age in Genesee County toward healthier dietary patterns using a socio-cultural and biomedical orientation. The PEN-3 model, which frames culture in the context of health promotion interventions, was integrated with the Transtheoretical Model to guide this 13-week pre-test/post-test curriculum. Materials developed included soul food plate visuals, a micronutrient availability worksheet, a fruit stand, and gardening kits. Learning activities included affirmations, stories, case-
\end{abstract}

S. Kannan $(\bowtie)$

Department of Nutrition, School of Public Health and Health Sciences, University of Massachusetts, 209 Chenoweth Laboratory, 100 Holdsworth Way, Amherst, MA 01003, USA e-mail: srimathik@gmail.com; skannan@nutrition.umass.edu

\section{A. V. Sparks}

Genesee County Community Action Resource Department, 605 N. Saginaw Street, Flint, MI 48503, USA

\section{J. D. Webster}

Department of Global and Community Health, George Mason University, 4400 University Drive MSN 5B7, Fairfax,

VA 22030, USA

\author{
A. Krishnakumar \\ Department of Child and Family Studies, College of Human \\ Studies and Health Professions, Syracuse University, Syracuse, \\ NY 13244-1250, USA

\section{J. Lumeng} \\ Center for Human Growth and Development, Department of \\ Pediatrics and Communicable Diseases, University of Michigan, \\ 300 North Ingalls Building 10th Floor, Ann Arbor, \\ MI 48109-0406, USA
}

scenarios, point-of-purchase product recognition, church health teams, and community health fairs. We investigated health-promoting dietary behaviors (consumption of more fruits and vegetables $(\mathrm{F} \& \mathrm{~V})$, serving more $\mathrm{F} \& \mathrm{~V}$ to their families, and moderating dietary sodium and fat intakes), and biomedical behaviors (self-monitoring blood pressure and exercising) across five stages of change. Session attendance and program satisfaction were assessed. $N=102$ women participated (mean age $=27.5$ years). A majority $(77 \%)$ reported adopting at least one healthy eating behavior (moderating sodium, serving more $F \& V$ to their families), $23 \%$ adopted at least two such behaviors (reading food labels for sodium; using culinary herbs/spices; serving more F\&V to their families), and $45 \%$ adopted both dietary (moderating sodium; eating more fruits) and biomedical behaviors. Participants and facilitators favorably evaluated the curriculum and suggested improvements. A multi-conceptual approach coupled with cultural and biomedical tailoring has potential to promote young African American women's movement to more advanced stages of change and improve self-efficacy for fruit and vegetable intake, dietary sodium moderation, and selfmonitoring blood pressure and physical activity.

Keywords African Americans - Stages of change Nutrition education materials - PEN-3 .

Nutrition curriculum · Women of childbearing age

\section{Introduction}

Infants born to African American women experience disproportionately high rates of mortality (IMR) and low birth weight (LBW) [1-4]. The U.S. government has made elimination of such disparities a stated national health 
objective for 2010 [4]. The national average for IMR in 2003 was 5.7 for whites and 14.0 for African Americans [5]. The percent of LBW live births is 13.1 for African Americans, compared to 6.5 for Whites [4]. The persistent 3- to 4-times greater risk of pregnancy-related mortality for African American women compared to White women is the largest gap among the traditional indicators of maternal and infant health in the United States. Racial disparities also exist for infant outcomes and they, like those for pregnancy-related mortality, remain largely unexplained [6-9].

Racial and Ethnic Approaches to Community Health (REACH) is the cornerstone initiative of the U.S. Centers for Disease Control and Prevention (CDC) aimed at eliminating racial/ethnic health disparities, with a particular focus on IMR, through population-focused and systemic structural interventions that embody cultural understanding, sensitivity and relevance [10]. The Precious Black Babies Initiative, a group of 14 multifaceted community interventions in Genesee County, Michigan, is one such REACH initiative [10]. This community was in particular need of such an intervention because Genesee County has among the highest IMR in Michigan [10]. IMR in this region increased significantly from 9.1 to 13.1 per 1,000 live births between 2001 and 2004 [10], and the racial/ ethnic disparities are among Michigan's highest [10]. When a perinatal periods of risk assessment (PPOR) was done in Genesee County in 2000, the most significant area of risk was found to be Maternal Health/Prematurity (Personal Communication, Leslie Lathrop, Fetal Infant Mortality Coordinator Review, Genesee County Health Department, November 2002).

Core themes for the REACH work in Genesee County include: reducing racism, enhancing the medical care and social services systems, and fostering community mobilization. Strategies include community dialogue and raising awareness, education and training, outreach and advocacy, and mentoring and support [1]. To date, there has been no attempt at targeted nutrition education to reach African American women of childbearing years to improve birth outcomes in this community. Prior research in this community confirmed the need for nutrition workshops and culinary skill building classes [11]. Younger women expressed creativity with recipes, and presented a desire to be more involved with preparing foods. Older women expressed eagerness to teach family-centered culinary classes. Both groups of women acknowledged time and budget barriers, identified the prevalence of lactose intolerance and recognized that large grocery stores that offered food variety were not located in their community (Fig. 1) [11].

Nutrition was a primary focus of the Precious Black Babies Initiative, given that African Americans have a

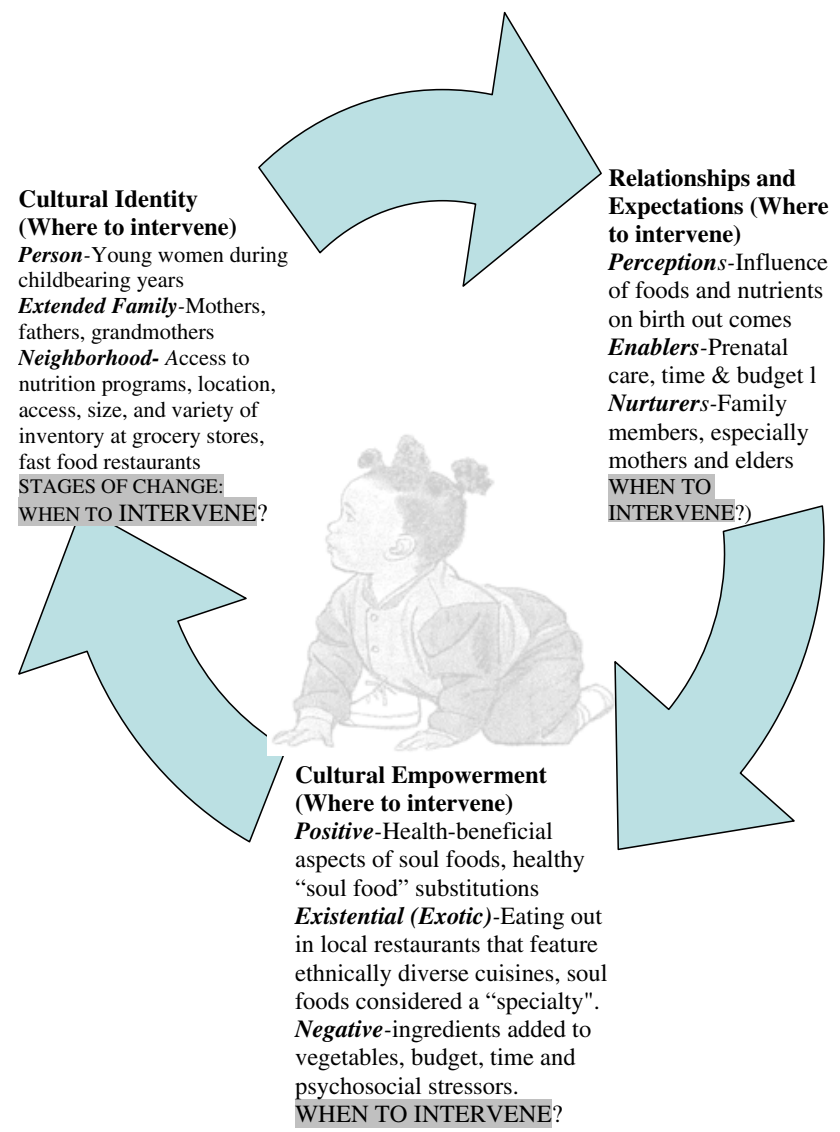

Fig. 1 PEN-3 domains and constructs [34, 35] and focus group findings [11] as applied to the healthy eating and harambee curriculum

higher prevalence of diet-related chronic diseases [12-16]. Studies show that African-Americans have lower fruit and vegetable intake than do non-Hispanic whites, Hispanics, and individuals of other ethnic-racial origins, and, like other U.S. ethnic-racial groups, their average intake decreases with income [17-22].

Pre-pregnancy is a time when attention to nutrition can reduce the risk of future obesity, diabetes and cardiovascular disease (CVD). Research findings underscore the importance of consumption of micronutrient rich food sources, such as fruits and vegetables $(\mathrm{F} \& \mathrm{~V})$ for improving birth size. The period of transition to motherhood is an opportune moment for intervention, given the public health programs available to women during this period, and often their natural interest in optimizing their own health and nutrition during pregnancy for the benefit of the child.

The improvement of nutrition in a population that is disproportionately burdened by poor birth outcomes and by chronic diseases is extremely important to the Maternal and Child Health $(\mathrm{MCH})$ field. For example, in pregnancies complicated by diabetes, high concentrations of glucose, particularly after a meal, give rise to an increased nutrient 
transfer to the fetus and adversely influence birth weight and pregnancy complications [23]. Culturally acceptable food sources of the micronutrients iron, calcium, folic acid and zinc are integral for fetal growth and development and maternal micronutrient malnutrition may lead to adverse birth outcomes [24, 25]. Similarly, circulating concentrations of alpha-tocopherol are positively associated with fetal growth [26].

Randomized culture-sensitive community trials in lowincome populations have tried to modify multiple dietary risk factors for chronic disease prevention and have demonstrated small changes [27]. While there have been many documented efforts to improve nutrition among racial/ethnic groups [28-33], there have been few attempts to incorporate theoretical models with a cultural basis in these efforts reflecting the ethnic beliefs, values, customs, food preferences, learning methods, and health care practices of African American women. Developing such programs requires the identification of theories that inform the cultural process of dietary change. In this paper, we describe Healthy Eating and Harambee, one such multi-theoretically grounded, historically- and socio-culturally-centered and biomedically oriented program to reach African American women of childbearing age. The word Harambee originated in Kenya, and in Swahili refers to people "pulling together" to build communities. This culturally embedded concept served as a driving focus of the program.

\section{Goals and Objectives}

The purpose of this project was to develop, implement and evaluate a peer-led nutrition curriculum that addresses established objectives of maternal health, and to shift the stage for African American women of childbearing age in Genesee County toward healthier dietary patterns using a socio-cultural and biomedical orientation. The curriculum will be used for Healthy Eating and Harambee.

Specific objectives were to (1) design Healthy Eating and Harambee Dinners and explore the application of PEN-3 model (described under Methods; Fig. 1) in helping to reduce nutrition risks (e.g., dietary sodium and fat consumption) and enhance protective nutrition (e.g., F\&V intakes, use of culinary herbs and spices as substitutes); (2) analyze changes in self-efficacy and stage for the potential adoption of select dietary and biomedical behaviors; (3) determine the relationship between stage of change and processes of change and self-efficacy for select nutrition and biomedical variables; and (4) assess the usefulness of the multi-conceptual curriculum for nutrition education efforts.

Building on the extant literature, in the analysis presented here we postulated that Healthy Eating and
Harambee will (1) help to enhance women's sense of personal confidence to make healthy food selections and their values about the nutrition links with disease prevention, both by adding to their repertoire of activities and healthier food selections and by teaching them skills that include hands-on activities and the selection and preparation of foods for themselves and their families; (2) equip women with experience in dietary and biomedical selfmonitoring and goal setting to effect changes in their existing habits; (3) help shift from pre-action to an action stage (either action or maintenance); and (4) promote changes in the women's environmental support for healthful eating by introducing new role models, providing multiple opportunities for consumption of healthy foods, attempting to influence family food selections, trying to reduce the barriers to healthful eating, and creating peer support for healthier foods.

The purpose of this article is to delineate the peer-led curriculum-based program, specifically: (1) the theoretical, bio-medical and cultural rationale of the curriculum, (2) the process used to construct the curriculum, (3) the curriculum components, and (4) lessons learned.

\section{Methods}

Theoretical and Cultural Rationale of the Healthy Eating and Harambee Curriculum

The curriculum was built around the three interrelated domains and nine constructs in PEN-3 [34, 35; Fig. 1]: Cultural Identity, Relationships and Expectations and Cultural Empowerment. The model is illustrated in categories that form the acronym PEN for each of the three dimensions (See Fig. 1). The first dimension of the PEN-3 model is Health Education. An explanation for the acronym in this first dimension is: P-Person; E-Extended Family; and $\mathrm{N}-$ Neighborhood. The second dimension of the PEN3 model is the Educational Diagnosis of Health Behavior. The factors of the second dimension are: P-Perceptions; $\mathrm{E}-$ Enablers; and N-Nurturers. The third and most crucial dimension of the PEN-3 Model is the cultural appropriateness of health beliefs. The three factors in this final dimension are: $\mathrm{P}$-Positive; E-Exotic; and $\mathrm{N}-$ Negative.

PEN-3 [34, 35] was initially developed and applied in African countries, and later adapted to the African American culture. The model emphasizes culture as the key component related to health behavior and was developed to assist with the planning, implementation, and evaluation of culturebased health interventions [36-40]. This model has been applied towards understanding the cultural basis for cancer prevention efforts targeting African American women [37], a hypertension initiative targeting older African Americans, 
and HIV prevention and support efforts in South Africa and the United States [38-40]. PEN-3 has been used to explore how culture and community impact nutrition attitudes and food choices of a select group of African Americans in north central Florida [36]. However, PEN-3 has not yet been applied in the design of a nutrition curriculum as was done in the current project.

\section{Process Used to Construct the Curriculum}

The curriculum was informed by (1) main themes from focus groups with women residing in the target zip code areas (Fig. 1); (2) feedback from existing community programs such as the Special Supplemental Nutrition Program for Women, Infants and Children (WIC), churches, and community kitchens; (3) review of existing data on the epidemiology of maternal health in that community; (4) Dietary Guidelines for Americans [41]; and (5) Sisters Together: Move More, Eat Better [42], an existing Bostonbased nutrition and physical activity program for African American women.

The Principles of Community Based Participatory Research (CBPR) [43] guided the community engagement in the process. CBPR is defined as "systematic inquiry, with the participation of those affected by the issue being studied, for the purposes of education and taking action or affecting social change" [43]. The Healthy Eating and Harambee Steering Committee, composed of universitybased nutrition researchers, health care providers and representatives from area community health organizations, collaborated on all stages of curriculum planning and development. The program was advertised utilizing bulletin boards, community events mailers, newspapers, church circulars, billboards and pamphlets, newsletters, radio announcements, and bumper stickers. Women were recruited from local health departments, WIC, Early Head Start, Urban Garden and Land Use Committee, local university extension, and other REACH programs, such as Birth Sisters, and Maternal and Infant Health Advocacy Services (MIHAS). The Birth Sister initiative teaches local young women how to overcome obstacles that may arise during pregnancy, while helping the mother have a healthy baby and help that baby live beyond the age of one year. MIHAS helps mothers navigate the local baby health care system. Community partners also recruited participants from food pantries, grocery stores, church picnics, health teams, health clinics, prenatal and immunization clinics, beauty salons and social service organizations that serve low-income African American women. Women received personal invitations, letters, and telephone reminders from peer educators. Participants provided informed consent to take part in the curriculum.
The information obtained from the focus groups helped to identify senior women in the community as lead project facilitators, given that younger women recognized them as experts in cooking, nutrition, and health matters during pregnancy. Younger (19-25 years) African American Steering Committee members were trained to serve as assistant facilitators. Using a referral method, African American women residing in any one of the four target zip code areas were recruited from the following community organizations: Odyssey House Health Awareness Center, Neighborhood Roundtable, and Genesee County Community Action Resource Department (GCCARD), and the community at-large.

The Steering Committee used the Krueger [44] moderator and observer model to conduct the training. Teams of university- (technical expert) and community-based nutrition educators (community leader) conducted the training. A trained nutritionist served as the observer and note-taker. Program facilitators from the community were provided with a discussion guide including presentation slides, flowcharts, and talking points as well as answer keys. Trainings were designed to enhance nutrition knowledge, build problem-solving skills, improve teaching methods and efficiently manage group dynamics. Additional sessions also focused on cultural competency and food safety.

Throughout the curriculum cohorts, the steering committee community partners were paired with nutrition graduate students. The community partners learned about the PEN-3 model and stages of change and that the curriculum was based on focus group data, and then acted as peer educators in their respective roles as lead facilitators and co-facilitators. Several steps were taken to decrease the potential variability in the performance between lead facilitator and co-facilitator pairs. Facilitator pairs were changed once during the year, and other facilitators replaced those who were away because of illness. Cofacilitators still developing in their facilitation abilities were paired with a more experienced lead facilitator.

\section{The Curriculum Components}

Table 1 summarizes the 13 lesson topics and learning objectives focused on creating awareness of the established links between nutrition and maternal health. Table 2 presents sample materials in the curriculum including a variety of visual aids. Table 3 describes the learning activities that were created for the curriculum and how the focus group data and PEN-3 and stages of change model were utilized in the process. The interactive activities represent four learning styles: visual (seeing), kinesthetic (doing), affective (feeling/sensing), and cognitive (thinking). The experiential activities presented nutrition and disease prevention concepts through storytelling and case-scenarios. Each 
Table 1 Healthy Eating and Harambee curriculum topics and objectives

\begin{tabular}{|c|c|}
\hline Title & Objectives \\
\hline Introduction & $\begin{array}{l}\text { Learn the goals, initiative and structure of the project } \\
\text { Learn to keep food records }\end{array}$ \\
\hline $\begin{array}{l}\text { African American history in the context } \\
\text { of healthy eating }\end{array}$ & $\begin{array}{l}\text { Understand how African American history has influenced eating patterns/food choices that coincided } \\
\text { with history }\end{array}$ \\
\hline Basics of food and nutrition ${ }^{a}$ & $\begin{array}{l}\text { Learn the contributions of macronutrients, micronutrients and phytonutrients in healthy dietary } \\
\text { patterns }\end{array}$ \\
\hline Health promotion/disease prevention ${ }^{\mathrm{a}}$ & $\begin{array}{l}\text { Learn about high-risk diseases among African American women of reproductive age and infants } \\
\text { Learn the importance of consuming healthy food sources rich in essential micronutrients that will } \\
\text { positively impact the health of African American women of reproductive age and their babies }\end{array}$ \\
\hline Healthy food shopping ${ }^{\mathrm{b}}$ & $\begin{array}{l}\text { Learn to use the Nutrition Facts label to make healthier choices in the supermarket and become } \\
\text { familiar with serving size, calories, total fat, saturated fat, fiber, vitamins, and minerals on Nutrition } \\
\text { Facts panel through discussion followed by a hands-on activity }\end{array}$ \\
\hline Healthy dining & $\begin{array}{l}\text { Learn how to make healthier choices when eating out at fast food restaurants } \\
\text { Identify tips for not overeating when eating out, become aware of the calorie and fat content of fast } \\
\text { food items learn to recognize sources of micronutrients in specific fast food choices }\end{array}$ \\
\hline Vegetable gardening $^{\mathrm{b}}$ & Learn to grow, and harvest an array of fresh vegetables \\
\hline $\begin{array}{l}\text { Culinary herb gardening and } \\
\text { preservation }{ }^{\mathrm{b}}\end{array}$ & $\begin{array}{l}\text { Learn to grow, harvest and preserve culinary herbs } \\
\text { Learn to convert culinary herbs into spices }\end{array}$ \\
\hline Cooking with spices ${ }^{\mathrm{b}}$ & $\begin{array}{l}\text { Learn the antioxidant properties of spices } \\
\text { Learn to use culinary herbs and spices as substitutes for fat, salt and sugar }\end{array}$ \\
\hline Meal planning and preparation ${ }^{\mathrm{b}}$ & $\begin{array}{l}\text { Learn the benefits of making a weekly menu, preparing a well-balanced meal incorporating items } \\
\text { from the soul food pyramid, and learn time saving tips }\end{array}$ \\
\hline Body image and attitudes around food ${ }^{\mathrm{c}}$ & Raise awareness of the importance of having a positive body image \\
\hline Physical activity ${ }^{\mathrm{c}}$ & $\begin{array}{l}\text { Address basic physical activity goals and guidelines } \\
\text { Recognize health benefits of physical activity and its positive effects on health for women of } \\
\text { childbearing age }\end{array}$ \\
\hline Celebrating healthy eating: harambee & $\begin{array}{l}\text { Celebrate healthy eating and with the help of testimonials, showcase the healthy eating habits } \\
\text { developed as a result of this curriculum }\end{array}$ \\
\hline
\end{tabular}

Lessons with the same letter in superscript will be combined in future revisions of the curriculum based on process evaluation of the present pilot

module also included a Participant's Guide and a Facilitator's Guide, PowerPoint slides (overheads), and recommended readings. Written materials were set at a 6th-8th grade reading level, which was established using FleschKincaid [45]. More than half of the content in the final curriculum met this grade level. Consistent with the literature regarding the limitations of incorporating nutrients in nutrition communication, there was variability in the readability scores across the lessons in the curriculum, ranging between 4th (e.g., healthy eating tips) and 12thgrade (e.g., names of nutrients). Each lesson was to be taught at one-week intervals over a 13-week period, allowing enough time for participants to move through the stages of change. At the end of each cohort, a celebration dinner was held, which involved the participation of multigenerational community members, and included youth performances, a nutritious potluck, and presentations regarding the bridge between African and African American cultural foods. Participants and facilitators also provided testimonials highlighting their experiences with the curriculum.

\section{Evaluation}

The evaluation had several components: analyzing changes in self-efficacy and stage for select dietary and biomedical behaviors known to impact maternal and infant health; and assessment of participant and facilitator satisfaction with the curriculum.

\section{Outcome Evaluation}

Outcome evaluation was conducted using a pre-post test design based on the Transtheoretical Model (TTM) [46, 47]. The time frame between the tests was 13 weeks. The TTM has been beneficial to those interested in enhancing motivation for self-care. In this model, five distinct motivational stages of change are identified: pre-contemplation, 
Table 2 Healthy Eating and Harambee sample learning activities based on focus group findings and the domains and constructs of PEN-3

\begin{tabular}{|c|c|c|c|}
\hline Activity & Description of the activity & Focus group findings & $\begin{array}{l}\text { PEN-3 } \\
\text { domains and } \\
\text { constructs }\end{array}$ \\
\hline Namaste & $\begin{array}{l}\text { Read-aloud statements that instill positive affirmation (e.g., } \\
\text { Shoot for the moon-If you miss, you land among the } \\
\text { stars) }\end{array}$ & $\begin{array}{l}\text { Build relationships and promote positive } \\
\text { attitudes, beliefs, and values }\end{array}$ & Positive \\
\hline $\begin{array}{l}\text { Culinary herb } \\
\text { gardening }\end{array}$ & $\begin{array}{l}\text { Hands-on growing, harvesting and preserving a variety of } \\
\text { culinary herbs }\end{array}$ & Introduce multiethnic flavors & $\begin{array}{l}\text { Existential } \\
\text { extended } \\
\text { family }\end{array}$ \\
\hline Vegetable gardening & $\begin{array}{l}\text { Hands-on vegetable gardening, e.g., planting of seeds in a } \\
24 \text { " window box and tomato seedlings in } 16 \text { " round pots, } \\
\text { and learning to pick vegetables }\end{array}$ & "Show and Tell" how to grow vegetables & $\begin{array}{l}\text { Extended } \\
\text { Family }\end{array}$ \\
\hline $\begin{array}{l}\text { Point-of-purchase } \\
\text { product recognition }\end{array}$ & $\begin{array}{l}\text { Label reading for alternate calcium sources, fortified } \\
\text { cereals, fruit juices, breads, and pastas }\end{array}$ & Teach label reading for calcium & Positive \\
\hline Church health teams & $\begin{array}{l}\text { Pastoral messages focused on reading food labels, watching } \\
\text { portion sizes, using spices as salt-substitutes, and serving } \\
\text { the children fruit instead of candy for snacks/treats }\end{array}$ & $\begin{array}{l}\text { Incorporate spirituality into healthy eating } \\
\text { messages }\end{array}$ & Enablers \\
\hline Walking clubs & $\begin{array}{l}\text { Partnership with Flint Youth Violence Prevention, and } \\
\text { provided incentives to walking club participants from the } \\
\text { Healthy Eating Project, e.g., hats that converted to } \\
\text { reversible water proof hats in case of rain, matching water } \\
\text { bottles, pedometers, and fanny packs }\end{array}$ & $\begin{array}{l}\text { Link nutrition with existing community } \\
\text { sources for health promotion and disease } \\
\text { prevention resources }\end{array}$ & Neighborhood \\
\hline Fashion show & $\begin{array}{l}\text { Participants' description of their outfits and explained why } \\
\text { they feel good in them }\end{array}$ & $\begin{array}{l}\text { Teach how to set a good example for } \\
\text { children through healthy body weight/ } \\
\text { positive body image }\end{array}$ & Positive \\
\hline $\begin{array}{l}\text { Community health } \\
\text { fairs-healthy eating } \\
\text { partnership }\end{array}$ & $\begin{array}{l}\text { Physicians provided electrocardiograms (EKG's), Doppler } \\
\text { testing for strokes, information services and sponsored } \\
\text { cookbooks }\end{array}$ & $\begin{array}{l}\text { Link nutrition classes with community } \\
\text { resources }\end{array}$ & Neighborhood \\
\hline $\begin{array}{l}\text { Ask your neighbor: } \\
\text { what milk do you } \\
\text { drink? }\end{array}$ & $\begin{array}{l}\text { Learn to combine half a carton of milk with half a carton of } \\
\text { milk that had less fat. e.g., } 1 / 2 \% \text { or fat-free milk }\end{array}$ & $\begin{array}{l}\text { Show how to convert poor to good food } \\
\text { choices }\end{array}$ & Neighborhood \\
\hline
\end{tabular}

contemplation, preparation, action, and maintenance. Applications of the model have been reported in African American communities for smoking cessation [48] exercise [49] and dietary behavior [50]. However, to date, little research has been published applying the model in relation to pre-conception nutrition for African American women.

Specific staging questions were asked about sodium and saturated fat (dietary risk markers when consumed in excess) and F\&V consumption (dietary protective markers) (Table 4 lists the questions that were used for assessing sodium intake related stage). The biomedical behavioral markers included exercising behavior, and self-monitoring Blood Pressure (BP) measures (systolic blood pressure (SBP) and diastolic blood pressure (DBP) collected using a portable cuff device (Omron model \# HEM 711AC) that passed Association for the Advancement of Medical Instrumentation (AAMI) standards. BP was measured in a seated position using the right arm, with a large cuff used in instances where arm circumference was greater than 15 inches. Three consecutive measures of SBP and DBP were taken, with the mean of the 2 nd and 3 rd measures used for tracking by the participants. Participants received takehome BP kits and BP tracking forms.

\section{Process Evaluation}

During each session, observation logs and field notes were completed by the Steering Committee. In addition, participants and facilitators completed questionnaires at the end of each session (Table 5). The same 14 items were used on both questionnaires assessing their respective degree of satisfaction (scale 1-5) with the lessons (i.e, delivery, content, format, supplementary materials and activity sheets, usefulness for women of childbearing age, race/ ethnic and cultural applicability and relevance to the community). The participant questionnaire also included assessment of take-home activities. One item asked participants if they would recommend the classes to others. In addition, facilitators conducted brief interviews with participants at the beginning and end of each cohort, and project staff conducted weekly telephone interviews with facilitators, seeking feedback. 
Table 3 Healthy Eating and Harambee sample learning materials based on focus group findings and the domains and constructs of PEN-3

\begin{tabular}{|c|c|c|c|}
\hline Material & Description of the material & $\begin{array}{l}\text { Purpose inspired by focus group } \\
\text { findings }\end{array}$ & $\begin{array}{l}\text { PEN-3 } \\
\text { domains and } \\
\text { constructs }\end{array}$ \\
\hline $\begin{array}{l}\text { Soul food plate visuals, } \\
\text { food models, and } \\
\text { packages }\end{array}$ & $\begin{array}{l}\text { Demonstrations of how to prepare nutritionally balanced meals } \\
\text { for the family using the Soul Food Pyramid }\end{array}$ & $\begin{array}{l}\text { Demonstrate how to incorporate } \\
\text { nutrition knowledge when } \\
\text { creating meals }\end{array}$ & $\begin{array}{l}\text { Person/ } \\
\text { perceptions }\end{array}$ \\
\hline $\begin{array}{l}\text { Micronutrient } \\
\text { availability worksheet }\end{array}$ & $\begin{array}{l}\text { Evaluation of the availability of food sources of micronutrients } \\
\text { folate/folic acid in supermarkets and grocery stores }\end{array}$ & $\begin{array}{l}\text { Teach the importance of attaining } \\
\text { essential micronutrients }\end{array}$ & Positive \\
\hline $\begin{array}{l}\text { Healthy-food-shopping } \\
\text { story }\end{array}$ & $\begin{array}{l}\text { Tasting one new food product from the supermarket never tried } \\
\text { before and discussing the experiences in-class at the next } \\
\text { weekly session }\end{array}$ & $\begin{array}{l}\text { Encourage eating a variety of } \\
\text { foods, especially novel fruits and } \\
\text { veggies }\end{array}$ & Existential \\
\hline $\begin{array}{l}\text { Shape your family } \\
\text { history family tree }\end{array}$ & $\begin{array}{l}\text { Mapping out family's health history with worksheets provided } \\
\text { by the American Heart Association (2003) }\end{array}$ & $\begin{array}{l}\text { Incorporate "intergenerational } \\
\text { family-centered nutrition } \\
\text { activities" }\end{array}$ & $\begin{array}{l}\text { Extended } \\
\text { family }\end{array}$ \\
\hline Fruit stand & $\begin{array}{l}\text { "Fruit cart" supplied with seasonal and exotic fruits, ice, water, } \\
\text { and } 100 \% \text { fruit juice }\end{array}$ & $\begin{array}{l}\text { Teach how to incorporate exotic } \\
\text { fruits as part of daily foods }\end{array}$ & $\begin{array}{l}\text { Enablers/ } \\
\text { Perceptions/ } \\
\text { Existential }\end{array}$ \\
\hline Garden story & $\begin{array}{l}\text { Narrative experiences gardening with their grandparents, and } \\
\text { kids, or about their kids gardening in school }\end{array}$ & $\begin{array}{l}\text { Disperse nutrition knowledge and } \\
\text { experiences }\end{array}$ & Neighborhood \\
\hline Nutrition glossary & $\begin{array}{l}\text { Empowerment of participants to link nutrition science to healthy } \\
\text { eating }\end{array}$ & $\begin{array}{l}\text { Teach the meaning of nutrition } \\
\text { terms }\end{array}$ & Positive \\
\hline $\begin{array}{l}\text { List of scientific articles } \\
\text { and summary }\end{array}$ & $\begin{array}{l}\text { Elaboration of knowledge and recall of key concepts embedded } \\
\text { in the context of the lesson topics }\end{array}$ & $\begin{array}{l}\text { Provide summary results for } \\
\text { nutrition and birth outcomes }\end{array}$ & Perceptions \\
\hline Case-scenarios & $\begin{array}{l}\text { Identification of progressively broader and more } \\
\text { complexconcepts learned, exploration of them more deeply, } \\
\text { and application of principles ofevidence-based nutrition in } \\
\text { arriving at answers }\end{array}$ & $\begin{array}{l}\text { Teach how to use nutrition } \\
\text { knowledge to solve nutrition } \\
\text { problems }\end{array}$ & Nurturers \\
\hline $\begin{array}{l}\text { Nutrition and } \\
\text { biomedical tracking } \\
\text { form }\end{array}$ & $\begin{array}{l}\text { Self-recording their implementation of each new nutrition and } \\
\text { biomedical behavior for self or for family }\end{array}$ & $\begin{array}{l}\text { Teach how to keep track of daily } \\
\text { food choices }\end{array}$ & $\begin{array}{l}\text { Extended } \\
\text { Family }\end{array}$ \\
\hline
\end{tabular}

\section{Analysis}

Demographic data were collected at baseline by facilitatoradministered surveys. Participants in 2 classes $(N=23)$ and facilitators $(N=4)$ pre-tested the surveys for comprehensiveness, correct interpretation and length. Descriptive statistics were used to generate a demographic profile of respondents and to examine their stage distribution for $\mathrm{F} \& \mathrm{~V}$ consumption and sodium and fat intakes. Women were classified into one of five stages [51]. Those in the first three stages (pre-contemplation, contemplation, and preparation) were considered to be in pre-action, whereas those in the last two stages, in action (action, and maintenance). A staging score was created, in which 0 indicated no change, 1 indicated progression by one step (e.g., from Precontemplation to Contemplation/Preparation), and two indicated progression by two steps (i.e., from Contemplation to Action/Maintenance). Field notes and observation logs were reviewed by the Steering Committee for emerging themes. Participant and facilitator survey items were coded using "not at all satisfied" to "very satisfied" or "not at all useful" to "very useful" 5-point scales (Table 5), and mean scores were computed.

\section{Results}

The pilot study reported here involved a convenience sample of 18-45 year-old African-American, low income (defined as being eligible for public assistance) mothers residing in the targeted zip codes $48503,48504,48505$, and 48508 in Genesee County. Located in Southeast Michigan, Genesee County is the 5th most populous county in Michigan, with approximately 436,141 residents at the time of the study, of whom $20 \%$ were African American. The city of Flint is in the geographic center of Genesee County, with approximately 125,000 people, more than half of whom are African American. The University Institutional Review Board approved the study protocol.

During the 16-month pilot phase, 65 sessions were conducted, during which 102 women participated (mean age $=27.5$ years). Sixty-seven percent of eligible women approached $(n=153)$ agreed to participate. However, not everyone participated in all the sessions. The drop out rate was $20 \%$. Fifty-seven percent attended at least one session out of the 13 total sessions. Thirty-three percent reported education beyond high school and 23\% reported annual household incomes of $\geq \$ 35 \mathrm{~K}$. 
Table 4 Sample questions assessing stage of change [46] for Healthy Eating and Harambee participants: dietary sodium as case-example for staging algorithm

Do you consistently avoid eating high-sodium foods?

$Y e s$, I have been for more than 6 months maintenance

In the past 6 months, have you tried to eat foods with less sodium?

Yes, I have been, but for less than 6 months

Are you seriously thinking about less sodium over the next 6 months?

Yes, and I intend to in the next 30 days. preparation

$Y e s$, and $\mathrm{I}$ intend to in the next 6 months. contemplation

No, and I do not intend to in the next 6 months. precontemplation

Are you seriously thinking about preparing foods with low-sodium/salt for your family over the next 6 months?

Do you plan to continue trying to serve more fruits and vegetables for your family over the next 6 months? maintenance

Do you plan to continue trying to serve low-sodium foods for your family over the next 6 months? Maintenance

How confident are you that you can change your diet to less sodium? Self-efficacy

I can season foods with herbs and spices to lower the amount of salt (sodium) in my food

\begin{tabular}{ccccc} 
Very & Somewhat & No & Not & Not at all \\
confident & confident & opinion & confident & confident \\
Very & Somewhat & No & Not & Not at all \\
confident & confident & opinion & confident & confident \\
Very & Somewhat & No & Not & Not at all \\
confident & confident & opinion & confident & confident \\
Very & Somewhat & No & Not & Not at all \\
confident & confident & opinion & confident & confident \\
Very & Somewhat & No & Not & Not at all \\
confident & confident & opinion & confident & confident \\
Very & Somewhat & No & Not & Not at all \\
confident & confident & opinion & confident & confident \\
\hline
\end{tabular}

Pre-Post test results indicated movement through the stages of change. At baseline, $45 \%$ were in the Pre-Action stage for fat and sodium intakes, $40 \%$ for $\mathrm{F} \& \mathrm{~V}$ consumption, and less than $10 \%$ for self-monitoring BP and exercising. After participating in the Healthy Eating and Harambee program, a majority (77\%) reported adopting at least one health promoting dietary behavior (moderating sodium, serving more $\mathrm{F} \& \mathrm{~V}$ to their families), 23\% adopted at least two health promoting behaviors (reading food labels for sodium; using culinary herbs and spices; serving more $\mathrm{F} \& \mathrm{~V}$ to their families), and $45 \%(n=44)$ adopted both dietary (moderating sodium, and consuming F\&V and biomedical behaviors (self-monitoring BP, and exercising).

Facilitators (at the end of the project) were confident about teaching nutrition concepts to participants compared with when the project started. All facilitators were "proud of audience participation and rapport", and indicated that the curriculum motivated their (facilitators) self-interests in healthier eating. They added new workshops (e.g., include Servesafe, and Master Gardener), and created case scenarios that reflected their teaching and learning experiences, and shared these at the Harambee Dinners. One of the lead facilitators designed a fruit cart (Table 3), and introduced the participants to seasonal fruits like watermelon, mangoes and cantaloupe and staples such as oranges, grapes and bananas. Another lead facilitator demonstrated initiative by accessing the local agriculture database for nutrient composition for the fruits and used this information to create and distribute fruitcart handouts to the study participants.

Eighty-six participants (84\%) and all facilitators completed and returned the curriculum satisfaction surveys. The mean scores for the surveys completed across the 13 weeks is shown in Table 5. Mean scores ranged from 3.6 to 4.4 for participant surveys and 3.2 to 4.3 for facilitator responses. Eighty-five percent rated the lessons as "very useful" or "useful" and were "satisfied" with the lesson content and format; $100 \%$ would recommend the program to others. Similarly, among the $50 \%$ who at baseline did not report to already have a healthful dietary pattern for fruits and vegetables, $100 \%$ would recommend the program, while $76 \%$ of the already "healthful dietary pattern" would do so. A few $(<20 \%)$ women said that their participation in the program helped them select and pack healthier snacks for their children's lunch. Approximately $25 \%$ reported some degree of difficulty with the lesson focused on health promotion and disease prevention. They preferred interactive discussions and recommended (1) that family tree be introduced as a take-home activity in the lesson preceding the health promotion lesson, thus enabling the participants to discuss this activity in-class, and (2) that visual images be incorporated to describe micronutrient deficiencies such as neural tube defects. 
Table 5 Evaluation Survey for Healthy Eating and Harambee (a) participants and (b) facilitators

Mean $\pm \mathrm{SD}^{\mathrm{a}}$

(a) Healthy eating and Harambee participants ${ }^{\mathrm{b}}$

1. How satisfied are you with the content of today's lesson?

$4.1 \pm 0.79$

2. How satisfied are you with the format of today's lesson?

$3.8 \pm 0.81$

3. How satisfied are you with the way that the lesson was taught today?

$3.9 \pm 0.44$

4. How satisfied are you that you that the facilitator for today's lesson was prepared for the lesson?

$3.7 \pm 0.58$

5. How satisfied are you that the facilitator is knowledgeable about the topics of today's lesson?

$3.9 \pm 0.72$

6. How satisfied are you with the set-up of the room for today's lesson?

$3.7 \pm 0.55$

7. How satisfied are you with the supplementary lesson materials (handouts, newsletters)

$3.7 \pm 0.68$

that were used in teaching today's lesson?

8. How satisfied are you with the overheads (slideshow) used in today's lesson?

$3.6 \pm 0.87$

9. How satisfied are you with the activities (herb gardening) and activity worksheets (family tree)

$4.4 \pm 0.43$

in today's lesson?

10. How satisfied are you that today's lesson covers topics that are interesting to you?

$4.3 \pm 0.27$

11. How satisfied are you that today's lesson is applicable to African Americans?

$4.2 \pm 0.55$

12. How useful is today's lesson for the residents of Flint?

$4.4 \pm 0.59$

13. How useful is today's lesson for women of childbearing age?

$4.0 \pm 0.66$

14. Would you recommend the classes to others? Yes/No

Yes $100 \%$

(b) Facilitators ${ }^{\mathrm{b}}$

1. How satisfied are you with the topics of today's lesson?

$3.8 \pm 0.84$

2. How satisfied are you with the format of today's lesson?

$3.6 \pm 1.1$

3. How satisfied are you with the way that you taught today's lesson?

$3.8 \pm 0.84$

4. How satisfied are you that you were prepared to teach today's lesson?

$3.7 \pm 1.1$

5. How satisfied are you that you are knowledgeable about the topics of today's lesson?

$3.8 \pm 0.84$

6. How satisfied are you with the set-up of the room for today's lesson?

$3.9 \pm 0.84$

7. How satisfied are you with the supplementary lesson materials that were used in teaching today's lesson?

$4.3 \pm 0.24$

8. How satisfied are you with the overheads used in today's lesson?

$3.2 \pm 1.92$

9. How satisfied are you with the talking points used in today's lesson?

$3.5 \pm 0.8$

10. How satisfied are you with the activities and activity worksheets in today's lesson?

$4.0 \pm 1.35$

11. How satisfied are you with participant's understanding of today's lesson?

$3.9 \pm 0.76$

12. How satisfied are you that today's lesson covers topics that are interesting to the participants?

$4.0 \pm 0.69$

13. How satisfied are you that today's lesson is applicable to African Americans?

$4.3 \pm 0.77$

a $0=$ No opinion; $1=$ Not at all satisfied; $2=$ Not satisfied; $3=$ Satisfied; $4=$ Very satisfied; $5=$ Didn't answer

b Eighty-six participants (84\%) and all facilitators completed and returned the curriculum satisfaction surveys

A majority of participants and facilitators found the amount of time for each lesson to be about right, but a substantial number (45\%) preferred it to be shorter. Specific suggestions included reducing the number of lessons by combining topics, converting select lessons (vegetable and herb gardening) to activities and handouts and including only one in-class activity per lesson. A majority $(70 \%)$ remarked that namaste (Table 2 ) at the beginning of each lesson was relaxing to the body and the mind. More than half of the participants found the published scientific references helpful, consistent with the literature reports confirming that the general public is in need of more background information to understand scientific materials $[52,53]$.
A majority of the women described the worksheets $(65 \%)$, handouts $(60 \%)$ and case scenarios $(70 \%)$, as interesting, and relevant to African American women. Participants used the words "enjoyable' and "informative" to describe the take-home activities on family history (70\%), herb gardening (80\%), vegetable gardening (75\%) and healthier dining out $(80 \%)$. As one woman remarked "she thought her family was making healthier choices when they chose a salad, then learned as a result of the Healthy Eating and Harambee program that their choice of dressings made their sodium intakes too high". Participants further noted that they became aware of the importance of reading food labels and paying special attention to their sodium intake when dining out. More than $40 \%$ reported that nutrition 
label reading activity was especially informative for learning how to meet their needs for micronutrients like folic acid and calcium. Others commented that they learned new and practical nutrition information, e.g., that soymilk is a great alternative to regular milk, and that eating colorful veggies and fruits contributed health-protection. Several women indicated that they liked the holistic focus of the curriculum and that as a result, they developed new skills for a healthy lifestyle such as effective methods of overcoming obstacles that impede success, how to be resourceful in the face of resistance, gaining a better understanding of strengths, learning how to check BP, learning that foods have vitamins, like vitamin $\mathrm{K}$, and also learning to shop for nutritious foods. Many women found the glossary (55\%) and weekly nutrition tips (60\%) helpful.

\section{Discussion}

Theoretical and Cultural Rationale for the Curriculum

As predicted, through the geographically relevant curriculum that also is culturally appropriate in its historical and traditional emphasis, guidance and acknowledgment of health beliefs and practices, we were successful in exploring the application of PEN-3 in helping to reduce nutrition risks and enhance protective nutrition. The analysis in this paper shows changes in self-efficacy and stage for the potential adoption of select dietary and biomedical behaviors, and the key learning objectives and strategies presented here should be validated in future work.

The work described here adds to a growing body of literature, describing innovative concepts of applying cultural principles programs designed to reduce nutrition risks and enhance protective nutrition relevant to biomedical needs (examples, lactose maldigestion and hypertension). On average, African Americans consume calcium and dairy foods at levels well below current recommendations [54]. We recognized this potential physiological barrier and recommended alternate strategies for meeting the needs for this micronutrient using culturally relevant food optionsat points of food purchase and preparation. Special consideration was given in the curriculum activities to the financial status of young African American women residing in the zip code areas and their ability to access healthy food sources, for example, distance from grocery stores/ transportation, and ability to grow own food. Nutrition educators are encouraged to collaborate with local supermarket and restaurant chefs and feature culturally relevant healthier foods. In order to achieve behavior change, learners must hear consistent messages from different people, in different contexts and repeatedly [55]. For example, the church health teams delivered weekly messages about the importance of reading food labels, portion sizes, and spices that can be used as substitutes for salt, sugar and fat.

The conceptual elements of both PEN-3 and Stages of Change were integrated in the curriculum. For example, increasing self-efficacy was identified as an important behavioral marker (stage of change construct) and an enabler (PEN-3 domain) to improve F\&V intake as well as reducing sodium in this population. Through the integrated application of stages of change and PEN-3, we learned that if these women experience the nutrition guidelines as achievable, then subsequent, very simple, biomedical selfmonitoring (e.g., BP, exercising) should be an easy next step to initial dietary changes. This should be validated in future work. Young women in the community were at different places in the Stages of Change process, as predicted. The simple choices of pursuing fat- and sodiumreducing and $(\mathrm{F} \& \mathrm{~V})$ enhancing strategies provided easy first steps. Also noteworthy is the finding that the Healthy Eating and Harambee team offered memberships to the fitness centers in local churches. Sixteen memberships were offered for one year, and walking clubs were established. Other community-wide activities in which the women took part were Walk-for-Warmth and Bowling-forWarmth. Participants were provided disposable cameras and CD-ROM pictures were made for record keeping.

\section{Lessons Learned}

Study findings provide strong support for community partnership methods. Community partners took a lead role to review, discuss, and interpret data, and in the preparation of narrative reports. The engagement of community partners elicited information for how the nutrition curriculum and dissemination should be structured. Peer-teaching models in nutrition education show participants highly value the experience $[56,57]$.

The pilot testing also revealed the limits to which standardization of a curriculum across cohorts is possible and provided a better understanding of the need to combine fidelity of delivery of the curriculum with flexibility to enable its implementation. Facilitators' responses to the 13 lessons showed a trend toward increased satisfaction with the lessons overall, with the participant' enjoyment of the lessons, and with their attainment of knowledge and skills as the weeks progressed. Classroom observation by the Steering Committee members complemented these responses, showing that the women participated actively in and enjoyed the lessons (particularly the herb garden and family history). The observers noticed, however, that some facilitators neglected to follow the complete lesson plan sometimes, either omitting parts of a lesson, or not using 
the facilitator guides. Others have reported similar findings for peer-led nutrition programs [57]. Interviews with facilitators revealed that although they enjoyed teaching the curriculum and favored the focus on cultural perspectives in nutrition, they desired more flexibility in how they taught the curriculum and also recommended offering refresher training in order to improve coordination and support for the program.

Process Evaluation taught us additional lessons about scheduling and implementation. Observation of the classes indicated that facilitator enthusiasm in promoting healthy eating varied substantially from cohort to cohort. Although feedback from 102 participants showed that $90 \%$ liked the curriculum in general, specific interactive and experiential activities received markedly high scores: $72 \%$ for Herb Gardening and 65\% for the Healthy Dining Case Scenario. Facilitators and participants acknowledged that the "Health Promotion" lesson was challenging to implement and follow respectively. The Healthy Eating and Harambee Steering Committee subsequently identified the need to work further with facilitators to eliminate the barriers to an effective presentation of this lesson, and revisions to the curriculum are also currently underway.

\section{The Process Used to Construct the Curriculum}

The integration of PEN-3 with Stages of Change within the context of CBPR yielded points of intervention (where to intervene; Fig. 1) alongside providing insight into readiness for new learning (Table 2). This may be best illustrated with the observation that both facilitators and participants began to gradually change from passive recipients of information to practitioners of new behaviors. They recommended adding learning strategies (e.g., spiritual) to the curriculum. Community activities were subsequently incorporated to raise community-wide awareness about nutrition and health among those in the preaction stage. Specifically, the curriculum activities and Harambee Dinners were designed to raise awareness about culturally acceptable food sources of iron, calcium, folate and zinc, while also describing the health impact of excessive macronutrients such as total dietary fat, saturated fat, and sodium and included culturally acceptable food preparations and recipe substitutions. Public health has a long history of encouraging peer education in different subspecialties including nutrition, to make community interventions more responsive to the arising needs [57]. Such an approach "provides the opportunity for communities and science to work in tandem to ensure a more balanced set of political, social, economic, and cultural priorities, which satisfy the demands of both scientific research and communities at higher risk" [58].

\section{The Curriculum Components}

The pre-conception nutrition education approach used in the Healthy Eating and Harambee curriculum is consistent with $\mathrm{CDC}$ recommendations for "interventions that aim to identify and modify biomedical, behavioral, and social risks to a woman's health or pregnancy outcomes through prevention and management, emphasizing those factors which must be acted on before conception or early in pregnancy to have maximal impact" [59]. Based on the linked process and outcome evaluation results, the curriculum may be viewed as a success particularly in its intended purpose to translate newly emerging science in pre-conception nutrition and nutrition during pregnancy by combining novel methods of dissemination with conventional approaches. The novelty of new information and new behavioral guidance each week also helped sustain participation. Using a translational approach, women enrolled in the program were introduced to evidence-based nutrition and chronic disease prevention. The Healthy Eating curriculum and other similar published work such as Omega Three for Baby and Me [52] serve as examples of how community nutrition education can be effectively linked to nutrition science. The multi-theoretical approach further ensured the consideration of cultural interplay with family influences. "When and with whom food is eaten is as important to African Americans as the particular food being consumed." $[20,21]$. MCH professionals working with young African women are encouraged to incorporate the message of healthy eating by focusing on intergenerational activities such as those implemented here.

It should be noted that the sample in this current pilot study was small, and limits the extent to which findings may be broadly applied to African Americans. The approach used for nutrition self-monitoring and biomedical assessment was suitable but limited since a full nutritional assessment would have included height and weight for a BMI and waist circumference or waist to hip ratio assessment.

\section{Conclusions}

Healthy Eating and Harambee will help to increase nutrition support in the community, and improve the pre-conception nutrition of African American women, and the future health of these women, their children, and families. Not only is healthy eating of high priority as it relates to birth outcomes, but it also comes at a time when investigators, nationwide, have called increasing attention to the prevention of chronic diseases. The curriculum incorporated a population health approach with holistic focus to build community resource capacity by linking nutrition 
with early intervention and Head Start, church based health promotion, community kitchens, parenting programs, etc. Reducing maternal and infant nutrition risks and enhancing their protective nutrition will require a culturally-centered biomedical and multi-theoretical approach.

Acknowledgments The Healthy Eating Project was funded by Ruth Mott Community Foundation. We are indebted to Dr. Collins Airhihenbuwa (Pennsylvania State University Department of Biobehavioral Health, College of Health and Human Development) for his guidance related to the application of the PEN-3 theoretical model that was instrumental in the design, development, implementation and evaluation of the Healthy Eating and Harambee nutrition education curriculum. We also thank the grassroots community organizations in the Flint area for their support and participation in this research project.

\section{References}

1. Pestronk, R., \& Franks, M. L. (2003). REACH TEAM, Healthy Start TEAM, PRIDE Team. A partnership to reduce African American infant mortality in Genesee County, Michigan. Public Health Report, 118, 324-335.

2. Barfield, W., Martin, J., \& Hoyert, D. (2004). Racial/ethnic trends in fetal mortality-United States, 1990-2000. Journal of the American Medical Association, 292(5), 559-561.

3. Hessol, N. A., \& Fuentes-Afflick, E. (2005). Ethnic differences in neonatal and postneonatal mortality. Pediatrics, 115(1), 44-51.

4. U.S. Department of Health and Human Services. (2000). Healthy People 2010 (2nd ed.). [with Understanding and Improving Health and Objectives for Improving Health, 2 vols.] Washington, DC: U.S. Government Printing Office.

5. Committee on National Statistics (CNSTAT). (2004). In Ver Ploeg, M. \& Perrin, E. (Eds.), Eliminating health disparities: Measurement and data needs, Panel on DHHS collection of race and ethnicity data (p. 23). The National Academies Press.

6. Armstrong, A., \& Maddox, Y. T. (2007). Health disparities and women's reproductive health. Ethnicity and Disease, 17(Suppl 2), S2-4-S2-7.

7. David, R., \& Collins, J., Jr. (2007). Disparities in infant mortality: What's genetics got to do with it? American Journal of Public Health, 97(7), 1191-1197.

8. Byrd, D. R., Katcher, M. L., Peppard, P., Durkin, M., \& Remington, P. L. (2007). Infant mortality: Explaining black/white disparities in Wisconsin. Maternal and Child Health Journal, 11(4), 319-326.

9. Alexander, G. R., Wingate, M. S., Bader, D., \& Kogan, M. D. (2008). The increasing racial disparity in infant mortality rates: Composition and contributors to recent US trends. American Journal of Obstetrics and Gynecology, 198(1), 51.e1-9.

10. Hunte, H. E., Turner, T. M., Pollack, H. A., \& Lewis, E. Y. (2004). A birth records analysis of the Maternal Infant Health Advocate Service program: A paraprofessional intervention aimed at addressing infant mortality in African Americans. Ethnicity and Disease, 14(3 Suppl 1), S102-S107.

11. Kannan, S., Webster, D., Sparks, A., Acker, C., \& Turner, T. (2009). Using a cultural framework to assess the nutrition influences in relation to birth outcomes among African American women of childbearing age: Application of the PEN-3 theoretical model. Health Promotion Practice, 10, 349-358.

12. Michigan Department of Community Health (MDCH). (2002). Number of infant deaths, live births and infant death rates by county of residence, 2001 and 1997-2001. MDCH Data Book.
13. Sharma, S., Murphy, S. P., Wilkens, L. R., Shen, L., Hankin, J. H., Monroe, K. R., et al. (2004). Adherence to the food guide pyramid recommendations among African Americans and Latinos: Results from the multiethnic cohort. Journal of the American Dietetic Association, 104(12), 1873-1877.

14. Mackenbach, J. P., \& Howden-Chapman, P. (2003). New perspectives on socioeconomic inequalities in health. Perspectives in Biology and Medicine, 46(3), 428-444.

15. Kant, A. K., Graubard, B. I., \& Kumanyika, S. K. (2007). Trends in black-white differentials in dietary intakes of U.S. adults, 1971-2002. American Journal of Preventive Medicine, 32(4), 264-272.

16. Kumanyika, S. K. (2006). Nutrition and chronic disease prevention: Priorities for US minority groups. Nutrition Reviews, 64(2 Pt 2), S9-14.

17. Kumanyika, S. K., Whitt-Glover, M. C., Gary, T. L., Prewitt, T. E., Odoms-Young, A. M., Banks-Wallace, J., et al. (2007). Expanding the obesity research paradigm to reach African American communities. Preventing Chronic Disease, 4(4), A112. Epub 2007 Sep 15.

18. Miklos, E. A., Brahler, C. J., Baer, J. T., \& Dolan, P. (2004). Dietary deficiencies and excesses: A sample of African American mothers and daughters eligible for nutrition assistance programs. Family \& Community Health, 27, 123-129.

19. Gary, T. L., Baptiste-Roberts, K., Gregg, E. W., Williams, D. E., Beckles, G. L., Miller, E. J., 3rd, et al. (2004). Fruit, vegetable and fat intake in a population-based sample of African Americans. Journal of the National Medical Association, 96, 1599-1605.

20. Airhihenbuwa, C., Kumanyika, S., Agurs, T., Lowe, A., Saunders, D., \& Morssink, C. (1996). Cultural aspects of African American eating patterns. Ethnicity \& Health, 1, 245-260.

21. Hargreaves, M. K., Schlundt, D. G., \& Buchowski, M. S. (2002). Contextual factors influencing the eating behaviors of African American women: A focus group investigation. Ethnicity \& Health, 7, 133-147.

22. Jackson, K. A., \& Savaiano, D. A. (2001). Lactose maldigestion, calcium intake and osteoporosis in African-, Asian-, and Hispanic-Americans. Journal of the American College of Nutrition, 20, 198S-207S.

23. Kim, C., McEwen, L. N., Kieffer, E. C., Herman, W. H., \& Piette, J. D. (2008). Self-efficacy, social support, and associations with physical activity and body mass index among women with histories of gestational diabetes mellitus. The Diabetes Educator, 34(4), 719-728.

24. Ramakrishnan, U. (2004). Nutrition and low birth weight: From research to practice. American Journal of Clinical Nutrition, 79(1), 17-21.

25. Underwood, B. A., Deckelbaum, R. J., \& Akabas, S. R. (2005). Women and micronutrients: Addressing the gap throughout the lifecycle. American Journal of Clinical Nutrition, 81, 1187S.

26. Scholl, T. O., Chen, X., Sims, M., \& Stein, T. P. (2006). Vitamin E: Maternal concentrations are associated with fetal growth. American Journal of Clinical Nutrition, 84(6), 1442-1448.

27. Sloane, D. C., Diamant, A. L., Lewis, L. B., Yancey, A. K., Flynn, G., Nascimento, L. M., et al. (2003). REACH Coalition of the African American Building a Legacy of Health Project Improving the nutritional resource environment for healthy living through community-based participatory research. Journal of General Internal Medicine, 18(7), 568-575.

28. Havas, S., Anliker, J., Greenberg, D., Block, G., Block, T., Blik, C., et al. (2003). Final results of the Maryland WIC Food for Life Program. Preventive Medicine, 37(5), 406-416.

29. Kumanyika, S. K., Adams-Campbell, L., Van-Horn, B., Ten Have, T. R., Treu, J. A., Askov, E., et al. (1999). Outcomes of a cardiovascular nutrition counseling nutrition counseling program in African-Americans with elevated blood pressure or cholesterol 
level. Journal of the American Dietetic Association, 99, 13801388.

30. Anderson-Loftin, W., Barnett, S., Bunn, P., Sullivan, P., Hussey, J., \& Tavakoli, A. (2005). Soul food light: Culturally competent diabetes education. The Diabetes Educator, 31(4), 555-563.

31. Williams, J. H., Auslander, W. F., de Groot, M., Robinson, A. D., Houston, C., \& Haire-Joshu, D. (2006). Cultural relevancy of a diabetes prevention nutrition program for African American women. Health Promotion Practice, 7(1), 56-67.

32. Pérez-Escamilla, R., Hromi-Fiedler, A., Vega-López, S., Bermúdez-Millán, A., \& Segura-Pérez, S. (2008). Impact of peer nutrition education on dietary behaviors and health outcomes among Latinos: A systematic literature review. Journal of Nutrition Education and Behavior, 40(4), 208-225.

33. Metghalchi, S., Rivera, M., Beeson, L., Firek, A., De Leon, M., Cordero-Macintyre, Z. R., et al. (2008). Improved clinical outcomes using a culturally sensitive diabetes education program in a Hispanic population. The Diabetes Educator, 34(4), 698-706.

34. Airhihenbuwa, C. O. (1995). Health and culture: Beyond the western paradigm. Thousand Oaks, CA: Sage.

35. Airhihenbuwa, C. O. (1999). Of culture and multiverse: Renouncing "the universal truth" in health. Journal of Health Education, 30, 267-273.

36. James, D. C. S. (2004). Factors influencing food choices, dietary intake, and nutrition-related attitudes among African Americans: Application of a culturally sensitive model. Ethnicity \& Health, 9, 349-367.

37. Erwin, D. O., Johnson, V. A., Trevino, M., Duke, K., Feliciano, L., \& Jandorf, L. (2007). A comparison of African American and Latina social networks as indicators for culturally tailoring a breast and cervical cancer education intervention. Cancer, 109(2 Suppl), 368-377.

38. Paskett, E., Tatum, C., Rushing, J., Michielutte, R., Bell, R., Long Foley, K., et al. (2006). Randomized trial of an intervention to improve mammography utilization among a triracial rural population of women. Journal of the National Cancer Institute, 98(17), 1226-1237.

39. Airhihenbuwa, C. O., \& Webster, J. D. (2004). Culture and African contexts of HIV prevention, care, and support. SAHARA Journal, 1(1), 4-13.

40. Airhihenbuwa, C. O., DiClemente, R. J., Wingood, G. M., \& Lowe, A. (1992). HIV/AIDS education and prevention among African-Americans: A focus on culture. AIDS Education and Prevention, 4(3), 267-276.

41. Report of the Dietary Guidelines Advisory Committee on the Dietary Guidelines for Americans. (2005). Hyattsville, MD: US Department of Agriculture.

42. http://win.niddk.nih.gov/sisters/index.htm. Accessed January 2003.

43. Israel, B. A., Schulz, A. J., Parker, E. A., \& Becker, A. B. (1998). Review of community-based research: Assessing partnership approaches to improve public health. Annual Review of Public Health, 19, 173-201.

44. Krueger, R. A. (1988). Focus groups: A practical guide for applied research. Newbury Park, CA: Sage.

45. Flesch, R. (1974). The art of readable writing. New York: Harper and Row.

46. Greene, G., Rossi, S., Rossi, J., Velicer, W., Fava, J., \& Prochaska, J. (1999). Dietary applications of the stages of change model. Journal of the American Dietetic Association, 99, 673-678.

47. Greene, G. W., Fey-Yensan, N., Padula, C., Rossi, S., Rossi, J. S., \& Clark, P. G. (2004). Differences in psychosocial variables by stage of change for fruits and vegetables in older adults. Journal of the American Dietetic Association, 104(8), 1236-1243.

48. Schorling, J. B., Roach, J., Siegel, M., Baturka, N., Hunt, D. E., Guterbock, T. M., et al. (1997). A trial of church-based smoking cessation interventions for rural African Americans. Preventive Medicine, 26(1), 92-101.

49. Martin, M. Y., Prayor-Patterson, H., Kratt, P., Kim, Y., \& Person, S. (2007). Characteristics of insufficiently active hypertensive Black women who volunteer to be in a physical activity promotion intervention: An application of social cognitive theory and the transtheoretical model. Ethnicity and Disease, 17(4), 604-610.

50. Di Noia, J., Contento, I. R., \& Prochaska, J. O. (2006). Application of the transtheoretical model to fruit and vegetable consumption among economically disadvantaged African-American adolescents: Preliminary findings. American Journal of Health Promotion, 20(5), 342-348.

51. Prochaska, J., \& Velicer, W. (1997). The transtheoretical model of health behavior change. American Journal of Health Promotion, 12, 38-48.

52. Troxell, H., Anderson, J., Auld, G., Marx, N., Harris, M., Reece, M., et al. (2005). Omega-3 for baby and me: material development for a WIC intervention to increase DHA intake during pregnancy. Maternal and Child Health Journal, 9(2), 189-197.

53. Rogers, S. L. (1999). Understanding audiences. In S. M. Freedman, S. Dunwoody, \& C. L. Rogers (Eds.), Communicating uncertainty: Media coverage of new and controversial science. Mahwah, NJ: Earlbaum.

54. Wooten, W. J., \& Price, W. (2004). Consensus report of the National Medical Association. The role of dairy and dairy nutrients in the diet of African Americans. Journal of the National Medical Association, 96(12 Suppl), 5S-31S.

55. Ammerman, A., Corbie-Smith, G., St George, D. M., Washington, C., Weathers, B., \& Jackson-Christian, B. (2003). Research expectations among African American church leaders in the PRAISE! project: A randomized trial guided by community-based participatory research. American Journal of Public Health, 93(10), $1720-1727$.

56. Taylor, T., Serrano, E., \& Anderson, J. (2001). Management issues related to effectively implementing a nutrition education program using peer educators. Journal of Nutrition Education, 33, 284-292.

57. Taylor, T., Serrano, E., Anderson, J., \& Kendall, P. (2000). Knowledge, skills, and behavior improvements on peer educators and low-income Hispanic participants after a stage of changebased bilingual nutrition education program. Journal of Community Health, 25(3), 241-262.

58. Hatch, J., et al. (1993). Community research: Partnership in black communities. American Journal of Preventive Medicine, 9(Suppl), $27-31$.

59. Johnson, K., Posner, S. F., Biermann, J., Cordero, J. F., Atrash, H. K., Parker, C. S., et al. (2006). Recommendations to improve preconception health and health care-United States a report of the CDC/ATSDR preconception care work group and the select panel on preconception care. MMWR, 55, 1-23. 